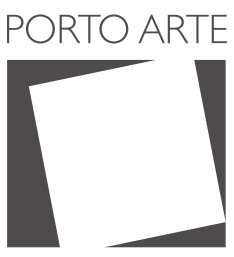

Revista de Artes Visuais

v. 24 ก. 40

jan/jun 2019

e-ISSN:2179-8001

ARTIGO E ENSAIO

\title{
Ícaro Estivalet Raymundo ${ }^{1}$
}

\section{Imagens cíclicas: GIF através do Vaporwave*}

Ciclic images: GIF through Vaporwave

\begin{abstract}
Resumo
Pretende-se aqui um recorte da paisagem virtual através dos aspectos imagéticos que são explorados pela estética Vaporwave, gênero artístico essencialmente digital surgido por volta de 2010. Mais especificamente, aborda-se o GIF, formato de arquivo de imagens, e os regimes de criação e visualização destes arquivos na web. Como desdobramentos da cultura visual digital, investiga-se ramificações e diferentes formas de manifestações do GIF para o Vaporwave.
\end{abstract}

\section{Palavras-chave}

Imagem. GIF. Vaporwave. Interface. Tela

\begin{abstract}
The intention here is to make a cut on the virtual landscape through the imagetic aspects that are explored by the Vaporwave aesthetics, artistic genre essentially digital emerged around 2010. More specifically, it approaches the GIF, image file format, and the regimes of creation and visualization of those files on the web. As deployments of the digital visual culture, it investigates branches and different ways of the GIF manifestation for Vaporwave.
\end{abstract}

\section{Keywords}

Image. GIF. Vaporwave. Interface. Screen 


\section{VAPORWAVE COMO PAISAGEM VIRTUAL}

As mudanças que as Tecnologias de Informação e Comunicação provocaram na sociedade estão em contínua formatação e assimilação, mas nestes últimos 20 anos já apontam marcas significativas. Quando quatro bilhões de pessoas acessam a internet, vemos a contemporaneidademarcada pelo uso de computadores e de celulares, onde a cultura do software é estendida para uma cultura do aplicativo, promovendo a interpretação de aspectos do mundo através de ferramentas e interfaces.

As imagens que evocamos em nossas telas diárias, por meio de instrumentos digitais que manipulamos e acessamos a internet, são paisagens virtuais que percorremos. Nelas, estão conteúdos linguísticos que associamos e reproduzimos, num exercício cognitivo que empreendemos continuamente e com mais intensidade (KERCKHOVE, 1997). Com as interfaces adequadas, podemos seguir vários caminhos concomitantes, coexistindo e os somando, vistos por janelas que ajustamos da forma que queiramos/sabemos. Traduzimos a realidade para o digital, e navegamos em uma temporalidade multidirecional (MONTAÑO, 2015).

Destas paisagens virtuais também acessamos seus sons, e da mesma forma da imagem, a escuta é controlável, podendo seus sons ser aumentados, consoados, distorcidos e silenciados. De meros espectadores, como tradicionalmente o cinema e a televisão percebem o seu público, tornamo-nos interatores (MACHADO, 2007), pois com a computação confere-se uma flexibilidade às obras, estando abertas a intervenções. No vasto ecossistema da internet, esbarramos com estéticas que nos são postas, conjuntos de cores e recursos visuais de plataformas, nutridas de arquivos das mais diferentes naturezas, ao mesmo tempo em que permite sua intervenção e customização. A cultura da internet abriu os mais variados nichos, pontos nevrálgicos de comunicação e compartilhamento dos mais diversos assuntos, gostos e saberes, numa paisagem suspensa por uma engenharia telemática.

Dentre estes vários nichos e peculiaridades da internet, busco com o nome Vaporwave delimitar uma abordagem digital contemporânea visual. 0 Vaporwave surgiu como um gênero musical por volta de 2010, com músicas feitas a 
partir de recortes e desacelerações de outras peças musicais, acoplados a uma forte carga iconográfica de identificação e de inspiração, criando uma atmosfera específica, recheada de rosa e azul, palmeiras e estátuas. Várias descrições tentaram apreender ou explicar o que a imagem e o som num geral evocam, e a palavra nostalgia é recorrente em pesquisas como de GraftonTanner, Mario Arruda, Marcelo Conter sobre o tema, assim como nos comentários e discussões em fóruns virtuais e redes sociais. As produções literárias sobre o Vaporwave, seja acadêmica ou vernacular, majoritariamente são oriundas da musicologia ou da comunicação, voltadas aos aspectos sonoros; neste caso, pretendo me deter na visualidade.

A definição de Vaporwave é controversa, podendo ser uma etiqueta artificial abrangente para designar uma série de aspectos estéticos audiovisuais de diversas obras. Cargas estéticas visuais são codificadas em figuras e motivos, e uma iconografia se estabelece em comunidades de redes, que interagem com fragmentos da cultura ocidental, triturados e achatados numa tela de cristal líquido. Simon Chandler, que em 2016 lançou várias matérias no site Bandcamp. com focando no assunto, aponta que:

Vaporwave não é somente um gênero; é uma abordagem e uma atitute - não só musica, mas cultura popular. Vaporwave é frequentemente identificado com sons particulares e estilizações - hits desacelerados e muzak dos anos 80 e 90 - embora o que é também essencial é a elevada auto-consciência, postura crítica que traz de sua fonte material. Ele remodela e reempacota, adicionando implicitamente camadas do tratado social. (CHANDLER, 2016, s.p.) ${ }^{2}$

A pluralidade de elementos visuais é complexa, mas como de acordo com Simon Chandler $(2016)^{3}$ e Maurício Fanfa $(2017)^{4}$ podemos apontar algumas características gerais como: palmeiras e a predominância do rosa, remetendo à artdecó da Miami dos anos 80/90; a presença de bens de consumo de uma vida capitalista da mesma época, (shoppingcenters, refrigerantes, computadores); paisagens estéreis e mundos idealizados, caracteres orientais; ou seja: uma miríade de códigos visuais que se expressam filtrados por glitches ${ }^{5}$ e saturações, remetendo a mídias obsoletas de um passado trancado numa memória recriada.

No âmbito visual, podemos apontar que objetos estéticos de Vaporwave se desdobram em: capas de álbuns, videoclipes em movimento, GIFs como videoclipes, ou simplesmente GIFs e imagens soltas que pululam sites e redes sociais como Reddit, 4Chan, Tumblr, Twitter, Instagram, entre outros.
2 - Vaporwave isn't just a genre; it's an approach and an attitude-not just to music, but to popular culture. Vaporwave is often identified with particular sounds and stylingsslowed arown hits and muzak from the '80s and '90s-yet what's also essential to it is the highly self-conscious, critical stance it takes to its source material. It remodels and repackages it, adding implicit layers of social commentary. (Tradução minha) Disponível em: <https://daily.bandcamp. com/2017/04/20/the-virtual-vaporwave-scene/>Acesso 28 jun 2018

3 - CHANDLER, Simon. Escaping reality: the iconography of vaporwave. 2016. Disponível em <https://daily.bandcamp. com/2016/09/16/vaporwave-iconography-column/> acesso em junho 2019.

4 - FANFA, Maurício. Formas próprias no imaginário da cibercultura, memória e Vaporwave 2017. Disponível em < https:// www.researchgate.net/publication/317850377> acesso em junho 2019.

5 - Glitch é o nome dado ao aspecto estético de um arquivo corrompido ou o resultado do mal-funcionamento de um dispositivo. Segundo Rosa Menkman (2011), é preciso estar atento as manifestações e formas que os glitches são explorados, e muitos deles percebidos como alcançados por softwares que simulam o glitch, e não realmente a partir do ruído de informação e do desgaste dos equipamentos e processos técnicos. 


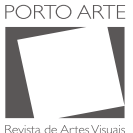

ARTIGO E ENSAIO
6 - Aqui é utilizado o Google em virtude de seu índex de sites e arquivos virtuais ser o mais completo que outros mecanismos de busca, como Bing e Yahoo. Vale lembrar que o sistema de organização de imagens do Google não é baseado nos conteúdos imagéticos de cada arquivo, e sim no nome em

que $\mathrm{o}$ arquivo foi assinalado.

Figura 1: Frame de GIF enquadrado como Vaporwave. Fonte: Printscreen feito do site Tenor. Disponível em: <https://tenor.com/view/ vaporwave-gif-11920868> acesso 22 mar 2019.

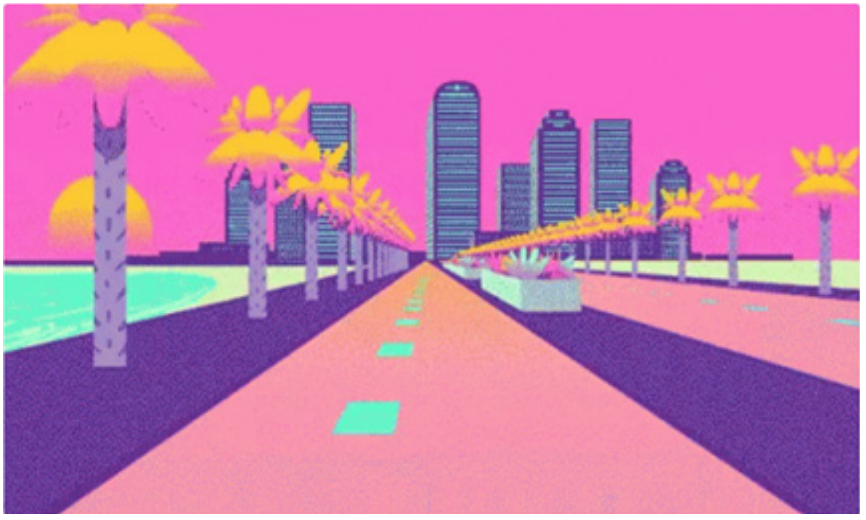
ras trazidas em cada produto visual.
Por mais que o Vaporwave traduza o mundo real em pixels e imagens coloridas, ele é um fenômeno típico da internet e da cultura digital, e como tal, explora recursos técnicos e estratégias estéticas típicas da era computacional. Estas imagens estão ligadas ao funcionamento da visualidade na internet, baseada em hipertexto, que possibilita acessos a diferentes janelas e arquivos e que radicalmente existem mediante a performance do computador (MANOVICH, 2001). Estas imagens de diferentes impactos e regimes visuais possuem uma mesma natureza digital e se manifestam mediante majoritariamente redes sociais, plataformas multimídia que veiculam materiais informáticos diversos. Por enquanto, faremos o recorde do Vaporwave através de apenas um formato de imagem, o GIF.

\section{NATUREZAS ABERTAS}

Sendo o Vaporwave um sintoma estético essencialmente virtual, ele incorpora os mecanismos de funcionamento do seu ambiente, a web, ou seja: sites, redes sociais, plataformas audiovisuais, que possibilitam formações de comunidades on-line. São dentro destas comunidades que o "imaginário" Vaporwave é elaborado e difundido. Com a melhoria de processamento de informações, memória dos dispositivos, e velocidade de conexão de redes, sofisticações tecnologicas assimiladas globalmente a partir de 2005, a imagem digital encontra-se em regimes de visualização mais dinâmicos.

Uma rápida pesquisa no Google ${ }^{6}$ sob o nome "Vaporwave GIF" repercute (pelo menos por volta de maio de 2019) em mais de 13.000 .000 de resultados, imagens associadas e indexadas como tal, a partir das cores, motivos e atmosfe-

Sendo a dimensão imagética fundamental para o Vaporwave, o GIF é um formato de imagem que oferece um versátil e impactante recurso para expressar ideias. A sigla GIF significa Graphics Interchange Format, sendo um formato de imagem Bitmap que opera com até oito bits por pixel, e também pode representar uma paleta de até 256 cores. São frames que tão rapidamente se sucedem que se torna uma pequena fração de vídeo, que permanece continuamente num ciclo, cujo corte final se mescla ao seu início. 
O GIF é mudo, puramente imagético, buscando uma brincadeira ilusionista de contínuo movimento,ou simples repetição eterna de uma cena específica. Segundo Miltner \& Highfied (2017), esse tipo de imagem é polissêmica e descontextualizada de sua origem, podendo comunicar expressões e ideias que encaixam em diferentes situações, substituem palavras, e integram o diálogo virtual, como são os GIF de reação (MILTNER\&HIGHFIELD, 2017). Atualmente seu emprego é majoritariamente explorado em redes sociais, dinamizado pelas tecnologias de informação e comunicação que permitem as pessoas a criarem estes arquivos e compartilhá-los. Tanto a criação quanto difusão estão ligadas a softwares, e à suas adaptações operacionais para dispositivos móveis, o aplicativo. O GIF propriamente dito, como formato de arquivo, aqui, será menos importante do que o conceber o GIF como um dispositivo hipertextual, um fenômeno cultural contemporâneo.

O efeito do GIF pode ser encontrado em diferentes situações e não necessariamente ter tal formato, ramificando suas performances e significados na web. No Tumblr, GIFs povoam a paisagem virtual do site, enquanto que no Youtube, plataforma audiovisual que simula players e canais (MONTAÑO, 2015), GIFs podem ser simulados em formato de vídeo. Abordando o Vaporwave, neste caso, trago frames de videoclipes que utilizam a natureza cíclica do GIF. Por mais que estejam em formato AVI ou MP4, eles apresentam a mesma lógica hipnótica e de baixa resolução do GIF.

George Clanton, que assina várias músicas como ESPRIT, emprega um GIF como um videoclipe no Youtube, prática que agiliza a criação imagética em movimento e nutre a janela que se abre no player digital. Quase como uma estratégia industrial e automática, ESPRIT preencheu o conteúdo do vídeo clipe da música SummerNight com um loop continuo de um carro deslizando por uma rodovia, numa paisagem de resolução 8 bits.

Em uma pequena fração de tempo somos jogados em uma corrida eterna, mesmo que o próprio GIF não seja harmônico na ligação de seu fim com seu início. 0 carro que percorre a estrada brutalmente dá um passo

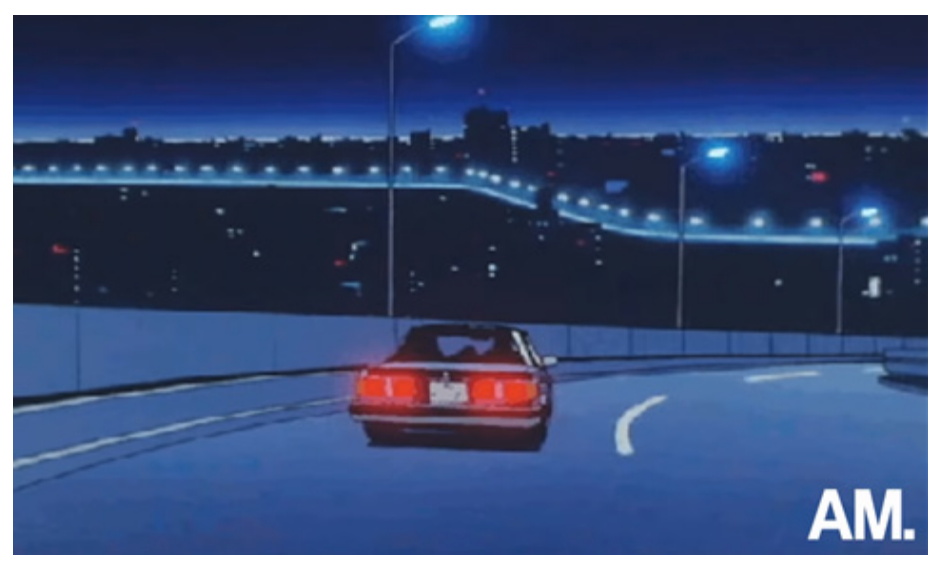
para trás em poucos segundos, nunca de fato de seguindo adiante, como que encapsulando uma volta de carro pela madrugada em uma rodovia vazia.
Figura2: Frame do videoclipe SUMMER NIGHT, de ESPRIT 空想 Fonte: Printscreen feito do vídeo no Youtube.

Disponivel em <https: //www. youtube.com/watch? $v=q s 7 \mathrm{kjvhwHIw}>$ acesso 16 mar 2019 . 


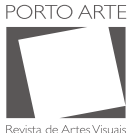

ARTIGO E ENSAIO

Figura 3: Frame do videoclipe da música SNAKE WAY 蛇の道 Fonte: Printscreen feito do videoclipe no site Youtube.com Disponível em :<https://www.youtube. $\mathrm{com} /$ watch?v=v7Srbp8WPMY> acesso mar 2019

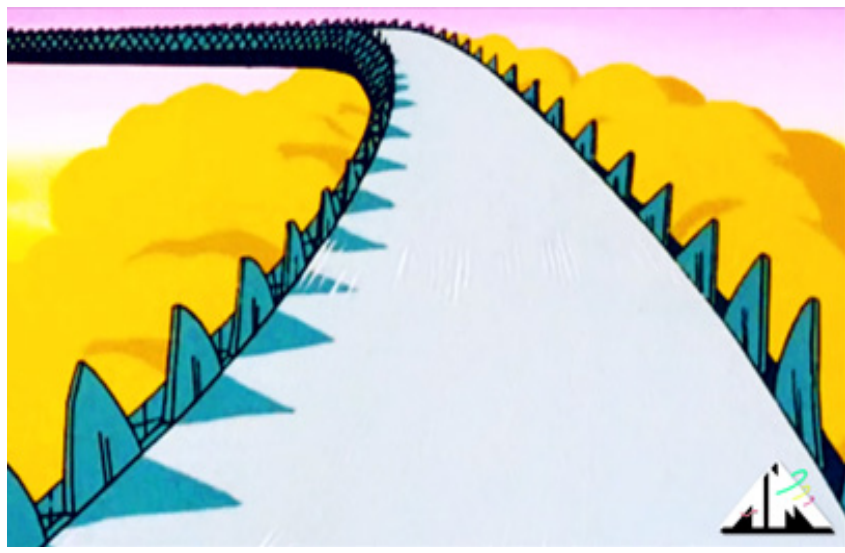

O mesmo efeito de continuidade é encontrado no videoclipe da música SNAKE WAY 蛇の道, do codinome MAITO, que se apropria de poucos segundos do famoso anime Dragon Ball, de Akira Toryama. O caminho da serpente, uma estrada de um mundo espiritual, é percorrido pelo personagem Goku por dezenas de dias, e o GIF evoca a sensação de estrada infinita que é encarada pelo personagem, como se fosse a nossa própria perspectiva a enfrentar o percurso. É válido lembrar que esta estratégia de utilização de GIF como um clipe é bastante difundido em gêneros musicais correlatos, como Chillwave, Vaportrap, e Lo-fiHip-Hop, e que tem alta influência de animes japoneses e desenhos animados.

Estes dois últimos trechos são extraídos de vídeos, em formatos adequados para a plataforma do Youtube. Ou seja, não são GIFs na sua essência: são transposições entre o que o GIF proporciona, uma imagem cíclica, de baixa-resolução, que é posta em funcionamento em outro formato de arquivo, neste caso MP4 ou AVI, empregado como um recurso visual agora acompanhado de som, como um videoclipe.

Todos os trechos aqui expostos tem uma característica em comum: todos são delimitados por uma tela, um retângulo que enquadra o cenário. Este aspecto é típico do GIF dos últimos anos, que se apropriam de trechos de filmes, ou filmagens de celular, para então serem salvos no formato. GIFs podem ser livres destes enquadramentos retangulares, aspecto encontrado em GIFs em suas primeiras experimentações, onde figuras eram coladas à página da internet, movendo-se livre de um enquadramento, sobrepostas ao fundo do site. Elaborado em 1987 por uma equipe da CampuServe, encabeçada por Alexander Trevor, o GIF era a chave para se fazer uploads de imagens em movimento nos anos 90 , cuja conexão com poucos kbps tornava inviável arquivos pesados. Quando a CampuServe foi comprado pela AOL em 1998, a patente do GIF entrou para domínio público, sendo então amplamente explorada por internautas.

A artista russa Olia Lialina foi uma das pioneiras na experimentação do formato GIF para suas obras de arte, sendo o projeto de web-art "Myboyfriend came backfromthewar" encontrando vazão na internet do final dos anos 90 por ser a melhor maneira de disponibilizar uma imagem em movimento na internet (GREENE, 2004). O GIF então pode ser quiçá apontado como um dos elementos mais marcantes para a história da imagem na internet e um elemento que acompanha esta cultura digital que na então década de 90 estava sedimentando-se e popularizando na sociedade ocidental. As primeiras experiências de navegação 
foram marcadas por este formato de imagem em movimento, uma estratégia de oferta de imagem com diversas funções e naturezas. Nas camadas de sites, estes GIFs poderiam servir de ilustração para um texto ou como armas para a caça de atenção do internauta, um objetivo que cada vez mais será exercitado ao ser percebido as relações entre estética e funcionalidade de um layout de navegação.

Conforme a sofisticação da estrutura telemática e a possibilidade de modelagem de sites e páginas, o GIF perdeu sua vantagem de leveza e formato viável de ilustração para ser um formato limitado de produção imagética digital. Em 2007, com o crescimento de sites como Tumblr, o GIF passou de uma imagem pixelada e cartunesca, com um fundo transparente que pudesse suspender a imagem a uma página da web, à pedaços de vídeos delimitados por retângulos, com cenas captadas e postas em loop. Toda sorte de material visual pode ser utilizado para um GIF, desde filmes ao pronunciamento mais recente discurso do presidente de um país. Atualmente, com os aplicativos de celulares, a criação de GIFs é automatizada e difundida de forma avassaladora, podendo ser feito num celular e ser postado na internet, e visto em computador, assim como o contrário. 0 formato conveniente para enviar imagens cíclicas assim integra-se ao repertório de interações visuais virtuais, onde a "combinação de contextos transcendentes, reforçando e estendendo significados através de repetição e remix, posiciona o GIF como peça-chave da língua franca da web social." (MILTNER\&HIGHFIELD, 2017, p.6) De uma estratégia sofisticada para colocar imagens em movimento na internet dos anos 90, o GIF passou à uma um formato muito conhecido e explorado deliberadamente pelas mais recentes gerações que vertem momentos, piadas, banalidades e coisas espetaculares em poucos cliques em um aplicativo.

Uma reformulação de sentido num cenário virtual cada vez mais acelerado no qual o uso do GIF será amplamente utilizado, principalmente a fins jocosos e de simbolismos através de imagens cíclicas. São expressos num recorte linear posto em loop (repetição sistemática), hipnótico ao seu momento clímax (uma pessoa caindo ou uma careta afetada) ser continuamente reexibido, convidando

o olhar a se demorar vezes e vezes sobre a cena. Suas cargas imagéticas povoam o ambiente virtual, de feed de notícias em redes sociais a compilados de grandes bibliotecas de GIFs, pequenos retângulos cíclicos que podem ser acessados tanto pela tela "retrato" do celular quanto pela tela formato paisagem do computador.
7: The combination of transcending context, and reinforcing and extending meanings through repetition and remix positions the GIF as a key part of the lingua franca of the social web. (Tradução minha). Disponivel em: <https:// journals.sagepub.com/doi/ pdf/10.1177/2056305117725223> acesso junho 2019pdf/10.1177/205 6305117725223> 


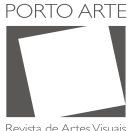

ARTIGO E ENSAIO
8 - Resposta do organismo ao ambiente. Segundo Kerckhove o sistema nervoso de mamíferos foi treinado a responder involuntariamente a estímulos internos e externos e mudanças no ambiente. (KERCKHOVE. 1997, p. 9

\section{TELAS COMO JANELAS ILUSÓRIAS}

O olhar é o sentido mais direto para o contato com a Web 2.0 e o seu ambiente reorganizável e não-linear. A tela é a ponta do iceberg, iluminando o olho enquanto sob a superfície de navegação há um bloco de códigos e operações, todas sendo feitas continuamente e remodelando o que se percebe pelo campo de visão.Em seu livro The Language of New Media, Manovich se aprofunda na trajetória da tela para a humanidade, e como ela desemboca tão presente no nosso cotidiano. Segundo o autor, as interfaces humano/computador tem como principal recurso de interação uma tela, pelo qual se obtém informações, sendo um espaço de representação, uma superfície retangular achatada que habita nossa realidade, um espaço corporal, onde no passado se pintava e criava figuras a serem contempladas. Na contemporaneidade, temos um aperfeiçoamento da tela, que atravessou aperfeiçoamentos e novas funções, ainda que ela mantenha traços genealógicos: a tela de tecido com seus dois gêneros de pintura, paisagem e retrato, até hoje são aludidas à funções contemporâneas, com a tela do computador em formato paisagem e o celular em formato retrato.

A tela se desenvolve ao longo da história, empregada em diversas funções, como no cinema, posteriormente na televisão e depois na informática; com imagens em movimento, e ainda mais acompanhadas de som, propõe-se outra mecânica de relação com o indivíduo que se permite entrar em contato com ela. No cinema, o espectador é convidado a imergir na ilusão, com as luzes apagadas e o silencio. A luz reflete na tela branca, e nossos olhos absorvem uma reflexão. A tela da TV, por sua vez, traz outro regime do olhar: ela em si emite a luz, assim hipnotizando o nosso olhar por nunca fechar um ciclo de Orienting Response $^{8}$. Com uma tela menor, onde a conversa é permitida e a imagem segue em movimento constante, sem um início, nem um fim. Quando a televisão de tubos é acoplada a engenharia informática nos anos 60, novamente acontece uma reformulação da função do olhar e da interação com o que se vê: a informação gráfica está sob o controle instantâneo do então interator: o computador fragmenta sua própria tela em diversas outras janelas que coexistem, e o espectador não se concentra numa tela só, rompendo o regime da tela dinâmica.

As fruições dos novos meios como televisão e computador são distintos, partindo de híbridos de gêneros, demandas e procedimentos. Com os novos meios digitais, são instaurados diferentes regimes de subjetividade. $O$ conceito de agenciamento foi desenvolvido a partir destas questões se referindo a necessidade do espectador de se sentir "assujeitado" para completar a "ilusão de imersão" 
(MACHADO, 2007, p. 135). Se a televisão desafiava a programação mental que adquirimos lendo e escrevendo, com sua sedutora atração que impossibilita o fechamento perspectivo, a internet oferece por este aspecto dois caminhos, um que abre janelas que por sua vez exibem algum material linear, mas possibilitando também a voltar e pausar, a linearidade temporal foi subjugada, permitindo um olhar que possa se deter, aumentar ou recuar. Não somente isso, mas num paralelo com a televisão, estes fatores se ressaltam, assim como a semelhança da natureza da tela que difere da do cinema, cuja luz rebate nos olhos.

Com a cultura da televisão dos anos 80 , tivemos uma educação que Kerckhove aponta como proporcionada pela tecnologia, sendo o zapeamento o início da nossa cultura de edição, assim como a gravação em vídeo nosso curso de produção. O VHS e barateamento de equipamentos possibilitou as pessoas a se expressarem por filme. Com teclado e mouse aprendemos a impactar o processamento de informações de forma interativa. Interface se tornou o lócus privilegiado de processamento de informação.

A televisão regeu a mente e a realidade mercantilizável da maior parte do mundo desde os anos 60, mas o "rápido crescimento de computadores pessoais desde o inicio dos anos oitenta demonstrou que a tela poderia também ser o foco de infinitas variações de produtos domésticos". Sendo assim, o desenvolvimento do $P C$ não é oposto, mas uma continuidade da TV. Machado percebe que com a sofisticação das tecnologias, os procedimentos ganham autonomia, esmaecendo a interação do operador das interfaces. Podemos ver este fenômeno estético no Vaporwave, onde as imagens foram submetidas a edições de softwares, que abrigam gigantes bibliotecas de filtros automáticos. Softwares e aplicativos automaticamente aplicam filtros e simulam glitches e o aspecto de VHS. Radicalmente, são atualizações de automatização impostas sobre a automatização da captação de luz, o que remonta à origem da fotografia no século XIX.

Essa automatização, por mais que exclua as intervenções do operador, não tira sua potencialidade como sujeito; pelo contrário, "o olhar é colocado para funcionar", reforçando o papel agenciador da visão:

"Em lugar de apagar-se e perder sua função, o sujeito torna-se a razão plena do ato da figuração: já não trata simplesmente de uma imagem, mas de uma imagem vista, de uma imagem que é visada, de um lugar originário de visualização, por algo/ alguém, que é uma espécie de sujeito maquina" (MACHADO, 2007, p. 138) 


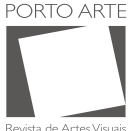

ARTIGO E ENSAIO

A automatização ocorre sem necessariamente o conhecimento do interator, tornando o aparelho no que Couchot e principalmente Flusser chamam de caixa-preta. Os processos maquínicos ocultos então estão no fundamento desse olhar exercitado, pois a figuração só é possível pela lógica da mídia em questão. Hardware e software compõem a caixa-preta do computador e do celular, e por meio dessas tecnologias que se fragmenta a tela tradicional em várias telas, onde as narrativas do cinema e da TV são subjugadas, estando a mercê da vontade do interator. 0 operador da interface então caminha para qualquer direção, e aciona imagens estáticas, em movimento, textos e áudios, cada qual um micro universo com suas respectivas linguagens e cargas simbólicas, mas suspensos à espera de sua reprodução. Os regimes do texto, do cinema, da televisão, do rádio, ficam todos concentrados na linguagem da nova mídia, todas codificadas e copiadas deliberadamente.

Por mais que muitas operações sejam automatizadas e seu processo maquínico oculto para nós, chegamos ao mesmo tempo no controle da ilusão. Acionamos arquivos por meio de links, e escolhemos quando vamos nos deixar levar por narrativas. 0 campo de possibilidades traz a interatividade como chave, sob o qual compreende o acionamento de objetos visuais simbólicos na medida em que eles acionam o operador através do que elas significam para ele. 0 termo interator aqui então é ressaltado: surgido no teatro alternativo e trazido às artes no ArsElectronica de 1992 por KristiAllik e Robert Mulder, o termo interator é usado por Claudia Giannetti em virtude das flexibilidades que a natureza digital concede aos objetos técnicos, possibilitando intervenções.

As Human/Computer Interfaces de Manovich são traduzidas por Giannetti como interfaces técnicas, entendidas como ferramentas que buscam reduzir as distancias do tempo de comunicação entre ação-reação. E estas ação e reação estão altamente ligadas à dimensão visual, pois "a vontade de otimizar o processo de interação e o tempo de reação sujeito-máquina redunda na potencialização da visualização e da percepção, a partir de outros sentidos humanos da informação" (GIANNETTI, 2006, p.120). É preciso observar que a tela não é mero campo no qual se desdobram jogos visuais, e sim se constitui como principal conexão entre humano/máquina, e a imagem produzida pelo dispositivo neste caso pertence a um novo regime do olhar, mas também de saberes e potências do interator sobre a obra ou sobre o que vê.

Ao ver um GIF, uma imagem infográfica projetada por um aparelho sob uma lógica interna de funcionamento, o interator (assim como o espectador de um filme), irá dar o sentido para aquela imagem de acordo com diversos fatores psicológicos, de afinidade, conhecimento, apreciação, repulsa e até indiferença. Mas há outro patamar de interação, e que amplia essa sistemática reduzida de emissor/receptor para comunicação e relação obra e indivíduo: a própria cultura 
visual da internet, pululada de fragmentos de outras imagens, de rostos e paisagens, propagandas e botões, vídeos e memes, convida à sua autofagia, a digestão de sua própria carne, fragmentando o seu material e transfigurando suas partículas em seus empregos e possibilidades estéticas.

GIF são polissêmicos, majoritariamente por serem fragmentos isolados de textos maiores. Isso, combinado com sua repetição e looping sem fim, permite-os veicular múltiplos níveis de significado em um único GIF. Esta complexidade simbólica faz deles uma ferramenta ideal para valorizar dois aspectos essenciais da comunicação digital: a performance do efeito e a demonstração de conhecimento cultural.

(MILTNER\&HIGHFIELD, 2017, p. 2-3) ${ }^{9}$

O GIF então faz parte de todo uma prática virtual e uma linguagem que explora recursos imagéticos em movimento, e que por sua natureza numérica, está aberta à intervenção e reconstrução, e também de criação de novos GIFs a partir de novos materiais, novas filmagens. $O$ interator dá sentido ao ver algo flutuando no arquivo da web, e pode dar algo a ser visto por outros, transformar algum frame ou cena em GIF e enviar para pessoas através de redes sociais.

A tela corresponde a um elo que possibilita essa fruição técnica e poética, de manifestação e exploração artística que deriva de processos sistemáticos de controle e modulação do material informacional, cada vez mais assimilado pela sociedade. Uma cultura eletrônica que transforma em visíveis diversas táticas de comunicação interpessoal e híbrida, e um treino no olhar para absorver pequenas doses de uma informação visual concentrada.

\section{ARREMATES}

A tela como superfície retangular que concentra informações está entranhada na cultura humana, mas no último século estruturamos relações muito próximas com uma tela dinâmica e ilusória, exercitando formas de olhar e interagir com a informação trazida. Do cinema, passando pela televisão e até o computador, a forma de percepção através do olhar foi reformulada em diferentes instâncias. Da ilusão da projeção de luz que reflete numa superfície (projeção de uma película), passa-se a uma ilusão estimulada por emissão de luz de uma tela de tubos, e posteriormente, em telas de cristal líquido, mas cujo radical de tradução de sinal eletromagnético em imagem permanece o mesmo: um mosaico de pontos que se ordenam mediante os sinais e simulam figuras e movimentos.
9 - GIFs are polysemic, largely because they are isolated snippets of larger texts. This, combined with their endless, looping repetition, allows them to relay multiple levels of meaning in a single GIF. This symbolic complexity makes them an ideal tool for enhancing two core aspects of digital communication: the performance of affect and the demonstration of cultural knowledge. (Tradução minha). Disponível em < https:// journals.sagepub.com/doi/ pdf/10.1177/2056305117725223> Acesso junho 2017. 


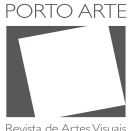

ARTIGO E ENSAIO

A televisão progride ao computador, e reconfigura as possibilidades de relação entre o individuo e a imagem. A possibilidade de intervenção na imagem computacional transforma o espectador tradicional do cinema e da televisão em interator, que eficientemente intervém e modula imagens, redimensiona-as e as distribui em novos formatos, como MP4, AVI, e GIF. Deste último formato, aponta-se uma distinta natureza de imagem, que hibridiza a imagem estática e com movimento, numa linearidade curta que paradoxalmente atinge o infinito. A linearidade do cinema, com início, meio e fim de um filme, ou a linearidade da televisão, que ininterruptamente oferece imagens em movimento em seus variados canais, são aqui postas em contraste com a linearidade do GIF: imagem em movimento e que ciclicamente liga o início ao seu fim, e à facilidade atual em se construir esse tipo de imagem e de arquivo.

O formato GIF em sua gênese tem uma função prática de ser a alternativa mais viável para se colocar uma imagem em movimento numa internet com conexões de poucos kbps como o cenário informático dos anos 90 demandava; conforme as tecnologias se desenvolvem e se sedimentam no ethos contemporâneo, o GIF apresenta diferentes comportamentos dos daqueles de sua origem: é agora mais fluído, imediato, de concentração de uma informação em uma imagem em movimento, quase como vídeos curtos de poucos segundos que podem ser postos em loop contínuo. 0 que antes era um elemento decorativo para páginas da internet no fim dos anos 90 , tornou-se um concentrado estético cíclico, que ignora a necessidade de um botão de acionamento, pois ele em si se movimenta. De função humorística à concentração de um movimento de um atleta que executa um lance espetacular em um esporte, o GIF fica atento aos corpos, às faces, às figuras, aos momentos captados por uma câmera, e os prende em círculos, para ciclicamente seu fim e seu início se unirem.

o GIF então pode ser aproximado aos antigos zoopraxiscópios de Eadweard Muybridge, fotógrafo do século XIX, que capturou movimentos de animais e os projetou de forma a criar uma ilusão de contínuo movimento, borrando qualquer noção de início e fim da imagem. A natureza do GIF é um eco de uma estratégia de captação e reprodução de imagem mais antiga que a televisão e o cinema em si, embora estes não apresentem algo de semelhante aspecto. As samsaras infinitas do GIF ou do zoopraxiscópio se aproximam, embora o regime de olhar do GIF vá além e represente em seu sentido histórico outra dimensão de intervenção, modelagem e difusão de imagem.

Para se chegar ao GIF, partimos do gênero musical Vaporwave, que como nome enquadra todo um universo sígnico que na internet traz pesada carga imagética, carga esta que encontra no GIF mais um formato informático para utilizar como veículo de potências estéticas. O GIF representa um recurso imagético versátil, pois oferece uma praticidade e facilidade em criar uma imagem em 
movimento para ser empregado como um videoclipe. É importante frisar que esta estratégia de GIF como um videoclipe não é exclusividade do Vaporwave, e sim encontra eco em diversos outros gêneros musicais. Afim de delimitação no vasto campo imagético da internet, partir do Vaporwave proporcionou perspectivas únicas sobre o GIF. No caso das figuras aqui trazidas, foram pinçadas de obras associadas ao nome Vaporwave, seja pelos artistas e suas trajetórias, pela estética sonora que envolve a imagem, ou pela simples associação, conexão, estabelecida por meio de um nome. A figura 1, puramente visual, é o que concentra essa associação ao nome devido sua carga imagética que é associada ao Vaporwave por meio do processo discursivo, quase que pedagógico, que define a etiqueta sobre o design de tais imagens, processo este que é tecido por fóruns virtuais, como Reddit.com e 4-Chan, por sites de crítica de música, como Bandcamp e Wired, e autores como GraftonTanner e Simon Chandler. Deste cenário, as imagens são paisagens a serem observadas, e as duas que ocupam lugar como clipe estão em um diferente formato numérico, embora enraizada e e permanência estética do GIF, agora com áudio. Neste caso é deslocado de seu formato essencial, embora ainda carregue os aspectos gerais, de imagem cíclica ininterrupta (fig. 2 e 3). 0 GIF que permanece em seu formato GIF e é etiquetado sob a hashtag Vaporwave (fig. 1), apresenta uma situação ainda mais peculiar, pois em sua imagem silenciosa estão concentrados sinais estéticos que se referem a um gênero musical, embora em si mesmo ele não apresente nada de som.

As diferentes formas de respiração destes objetos estéticos na internet, e a forma com que nos relacionamos com eles, constituem interessantes pontos de aproximação e interpretação da cultura contemporânea. O GIF sinaliza o uso e o impacto da imagem sendo exercitados de forma híbrida, com regimes visuais que transitam entre a linearidade e a fragmentação de temporalidade, articulando os aspectos das novas mídias ao serem reproduzíveis e multiplicáveis (MANOVICH, 2001) e ao estarem suspensas na web até serem acionadas por hiperlinks, e invocadas as perfomances computacionais que fornecem tais imagens. Através da tela do computador e do celular, que emolduram as paisagens virtuais marcadas por designs de interfaces que mediam a interação do visualizador a ponto dele se tornar o criador de seus próprios caminhos de visualização e das imagens que ele próprio contribui ao sistema em que está integrado. 


\section{REFERÊNCIAS}

ARRUDA, Mario Alberto Pires de. Vaporwave: estetização da tecnologia pelo atravessamento de enunciados. Trabalho de conclusão de curso (Comunicação social: habilitação em jornalismo) Universidade Federal do Rio Grande do Sul. Oritentador: Alexandre Rocha da Silva. UFRGS, 2015.

CHANDLER, Simon. Escaping reality, the iconography of Vaporwave. 2017 On https://daily.bandcamp. com/2016/09/16/vaporwave-iconography-column/

COUCHOT, Edmond. A tecnologia na arte: da fotografia à realidade virtual. Porto Alegre: editora da UFRGS, 2003.

De MÈREDIEU, Florence. Digital and video art. Chambers harrappublishersltd, 2005

FANFA, Maurício de Souza. Formas próprias no imaginário da cibercultura, memória e vaporwave. XVIII Congresso de Ciências da Comunicação na Região Sul - Caxias do Sul - RS - 15 a $17 / 06 / 2017$.

FLUSSER, Vilém. Filosofia da caixa preta: ensaios para uma futura filosofia da fotografia - São Paulo: Annablume, 2011.

GAZANA, C. et al. Glitch: estética contemporânea visual e sonora do erro. In: Cultura Visual, n. 19, julho/2013, Salvador: EDUFBA, p. 81-99.

GREEN, Rachel. Internet art.Thames \& Hudson Ltd. United Kingdom, 2004.

GIANNETTI, Claudia. Estética Digital: Sintopia da arte, a ciência e a tecnologia. Belo Horizonte: Editora C/Arte, 2006.

KERCKHOVE, Derrick de. The skin of culture: investigating the new electronic reality. London: Kogan Page, 1997.

MACHADO, Arlindo. O sujeito na tela: modos de enunciação no cinema e no ciberespaço. São Paulo: Paulus, 2007, 250p.

MANOVICH, Lev. The Language of New Media:The MIT Press. 2001

_- (2016) Notes on Instagranism and mechanisms of contemporary cultural identity. On: http:// manovich.net/index.php/projects/instagram-and-contemporary-image

MENCKMEN, Rosa. The Glitch Moment(um). Network Notebooks series, Amsterdam, 2011.

MILTNER, Kate M., HIGHFIELD, Tom. Never gonna GIFyou up. Analysing the cultural significance of the Animated GIF. Social Media + Society. Jul-Sept - 2017. Sage. 2017.

MONTAÑO, Susan. Plataformas de video: apontamentos para uma ecologia do audiovisual da web na contemporaneidade. Porto Alegre: Sulina. 2015

\section{REFERÊNCIAS ONLINE}

ESPRIT 空想 - SUMMER NIGHT. Duração: 2:33 - 3.081.260 visualizações -

Disponível em <https://www.youtube.com/watch?v=qs7kjvhwHlw>

MAITRO - SNAKE WAY 蛇の道. Duração: 3:07 - 2.569.115 visualizações - Disponível em <https:// www.youtube.com/watch?v=v7Srbp8WPMY> 
PORTO ARTE

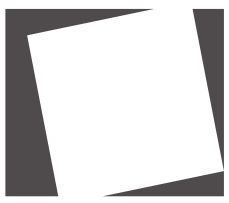

Revista de Artes Visuais

v. 24 n. 40

jan/jun 2019

e-ISSN:2179-8001.

ARTIGO E ENSAIO

\section{Ícaro Estivalet Raymundo}

Mestrando em História, Teoria e Crítica da Arte no PPG de Artes Visuais da UFRGS, voltado para investigação historiográfica de manifestações estéticas audiovisuais ocorrentes nas e através das novas mídias. 